\title{
Lifelong Learning as the Future Human Need
}

\author{
Oksana Voitovska \\ Ph.D., Associate Professor, National Pedagogical Dragomanov University (Kyiv, Ukraine) \\ E-mail: ovoitovskaya@ukr.net \\ https://orcid.org/0000-0002-1814-5895
}

\section{Svitlana Tolochko}

\author{
Ph.D., Associate Professor, National Aviation University (Kyiv, Ukraine) \\ E-mail: svitlana-tsv@ukr.net \\ https://orcid.org/0000-0002-9262-2311
}

\begin{abstract}
In the paper, the authors give a brief review of studies in the field of the neuroscience of consciousness in order to prove the following key point of the future human image: lifelong learning is the posthuman need. As well as new physical culture, which the authors have examined in the previous article, lifelong learning is the second key feature of the future human image. The authors have used the dialectical, scientific and formal logical methods of philosophy in order to fulfil the task. The novelty of the study is the substantiation of lifelong learning based on the neuroscience of consciousness, as well as the consideration of lifelong learning as a special culture that ensures the continuous development of the neural basis of consciousness. As a result of the study, the authors came to the following conclusions: a) lifelong learning is a special culture that provides continuous development of consciousness in ontogenesis; b) lifelong learning need as culture is due to dynamic neural basis of consciousness, which requires special conditions for full development in ontogenesis.
\end{abstract}

Keywords: lifelong learning; posthuman; neuroscience of consciousness; future human image; metacognition; high technology

Received: August 21, 2018; accepted: November 1, 2018

Philosophy and Cosmology, Volume 22, 2019: 144-151.

https://doi.org/10.29202/phil-cosm/22/13

\section{Introduction}

In the previous article Physical Education Teachers' Perspectives in a Changing World: From Future Studies to New Physical Culture, the authors have examined the physical education teachers' perspectives in a changing world. The authors have proved that the modern technologies of transhumanism aimed at expanding human biological capabilities and creating a posthuman, in which natural organs and organ systems are planned to replace

(C) Voitovska, Oksana, 2019

(C) Tolochko, Svitlana, 2019 
with artificial transplants. The comparative analysis of futures studies and studies in the field of physical culture, on the example of two specialized journals Future Human Image and Teaching in Physical Education, allowed the authors to conclude that physical culture and physical education would not lose their relevance in the future [Voitovska \& Tolochko, 2018].

In the present study, the authors would consider the achievements of neuroscience in the research of neuroevolution in order to prove the following key point of the future human image: lifelong learning is the posthuman need. As well as new physical culture, which the authors have previously examined, ${ }^{1}$ lifelong learning is the second key feature of the future human image.

\section{Current state of the neuroscience of consciousness}

The authors agree with Oleg Bazaluk, who argues that the future human image is based on the achievements in neurosciences [Bazaluk, 2015; Bazaluk \& Blazhevych, 2015]. In the Model "Evolving Matter", Bazaluk revealed the key stages in the neuroevolution and showed the place of human on the scale of the Earth and space [Bazaluk, 2016]. However, since the subject of our study is not the future human image in general, but only one of its defining characteristics, let us examine the neuroscience of consciousness. The authors, like Bazaluk, consider that all externals of human are due to the peculiarities of the structure and functions of his brain.

At present, the neuroscience of consciousness describes four basic theories (hypotheses):

1. The Global Neuronal Workspace. Bernard Baars first proposed the global workspace theory as a cognitive/computational model. However, according to Wayne Wu special attention should be given the neural version of Stanislas Dehaene and colleagues: a state is conscious when and only when it (or its content) is present in the global neuronal workspace making the state (content) globally accessible to multiple systems including long-term memory, motor, evaluational, attentional and perceptual systems [Wu, 2018].

2. Recurrent Processing Theory. Victor Lamme was the scientist who proposed the named theory in the beginning of the $21^{\text {st }}$ century. The theory describes different aspects of consciousness. Recurrent Processing Theory considers three different types of normal visual processing: (a) feedforward unconscious processing; (b) locally recurrent conscious processing (awareness), and (c) globally recurrent conscious processing which plays a major role in the mechanism of attentive selection.

3. Higher-Order Theories. The higher-order approach originated in philosophical discussion. Recently however, it has received substantial empirical support. Higherorder theories of consciousness argue that "conscious awareness crucially depends on higher-order mental representations that represent oneself as being in particular mental states" [Lau \& Rosenthal, 2011: 365]. In the paper Empirical Support for HigherOrder Theories of Conscious Awareness, the authors have considered Varieties of higher-order approaches to conscious awareness, and also "have reviewed empirical evidence that supports the higher-order view of conscious awareness and addressed empirically based challenges to the view" [Lau \& Rosenthal, 2011: 371].

4. Information Integration Theory of Consciousness. In the paper, which has become classic, An Information Integration Theory of Consciousness, Dr. Giulio Tononi revealed the key points of an Information Integration Theory. According to the theory, consciousness corresponds to the capacity of a system to integrate information.

${ }^{1}$ See [Voitovska \& Tolochko, 2018]. 
This claim is motivated by two key phenomenological properties of consciousness: differentiation - the availability of a very large number of conscious experiences; and integration - the unity of each such experience. The theory states that the quantity of consciousness available to a system can be measured as the $\Phi$ value of a complex of elements. $\Phi$ is the amount of causally effective information that can be integrated across the informational weakest link of a subset of elements. A complex is a subset of elements with $\Phi>0$ that is not part of a subset of higher $\Phi$ [Tononi, 2004].

Each of the above-mentioned theories has its own "strengths" and "weaknesses". All four theories are valid and continue to be developed in neuroscience. Unfortunately, none of the above-mentioned theories is able to reveal the neuroscience of consciousness. In fact, they complement each other, highlighting different aspects of consciousness work. However, the whole set of studies in the field of the neuroscience of consciousness allows us to highlight the key mechanisms of metacognition. The considered theories provide an opportunity to use the results of the neurobiological studies in modelling the future human image, as well as in building new educational technologies. They enrich philosophy of mind with new meanings, revealing neural basis of metacognition. It is essential to note that we understand metacognition as "the ability to think about our own thoughts, is a fundamental component of our mental life and is involved in memory, learning, planning and decisionmaking" [Grimaldi et al., 2015]. Metacognition has been examined in psychophysics, neuropsychology and neuroscience. Understanding the neural foundations of metacognition enrich Studies with non-human primates and rodents. For example, in the paper There Are Things That We Know That We Know, and There Are Things That We Do Not Know We Do Not Know: Confidence in Decision-Making, as a result of the comparative analysis, the authors concluded: "Imaging studies in humans as well as non-human animals can guide electrophysiological studies in animal models. Translating these approaches to electrophysiological experiments we believe will be at the root of understanding how the brain encodes confidence" [Grimaldi et al., 2015].

In general, based on the results of the neuroscience of consciousness studies, we should note the following points:

1. Introspection is probably the most studied manifestation of consciousness. Introspection is opposed to external observation. It is a human self-reflection, which combines the subjective and objective reports, based on the experience. In the paper Calibrating Introspection, Maja Spener proves the reliability of introspection for the study of consciousness [Spener, 2015]. Wayne Wu in considering introspection comes to the following important for our study conclusion: "Introspective reports demonstrate that the subject can access the targeted conscious state. That is, the state is access-conscious: it is accessible for use in reasoning, report, and the control of action. Talk of access-consciousness must keep track of the distinction between actual access versus accessibility. When one reports on one's conscious state, one accesses the state. Thus, access consciousness provides much of the evidence for empirical theories of consciousness" [Wu, 2018].

2. In the neuroscience of consciousness studies, there are continuing attempts to establish the neural correlates of consciousness, "the minimum neural mechanisms sufficient for any one specific conscious percept" [Koch et al., 2016: 307]. Obviously, establishing the neural correlates of consciousness would greatly facilitate a brain model creation and key mental functions description. The discovery of the neural correlates of consciousness would greatly strengthen the position of the materialists 
in Philosophy of mind. One of the last significant results in the search for the neural correlates of consciousness is the study of Neural Correlates of Consciousness: Progress and Problems. The authors found that the anatomical neural correlates of consciousness are primarily localized to a posterior cortical hot zone that includes sensory areas, rather than to a fronto-parietal network involved in task monitoring and reporting. Identifying correlates is an important step in understanding consciousness [Koch et al., 2016: 307].

3. In the neuroscience of consciousness studies, the attempt to connect introspection to attention is worth mentioning. Philosophical conceptions of introspective attention construe it as capable of directly focusing on phenomenal properties and experiences. In the paper A Taxonomy of External and Internal Attention, the authors underline that Attention is a core property of all perceptual and cognitive operations. For a more in depth study of attention, the authors suggested a taxonomy based on the types of information that attention operates over — the targets of attention. "At the broadest level, the taxonomy distinguishes between external attention and internal attention" [Chun et al., 2011: 73]. External attention refers to the selection and modulation of sensory information. Internal attention refers to the selection, modulation, and maintenance of internally generated information, such as task rules, responses, longterm memory, or working memory [Chun et al., 2011]. The taxonomy reveals modern understanding of neural mechanisms.

4. In understanding consciousness, the term access remains high on. Access is tied to attention. The term access specificity of understanding form the basis for the Global Workspace theory of consciousness, recurrent processing theory, etc. By studying the problem of access, the neuroscientists are trying to answer, why can there be phenomenal states that are not access conscious? Why is access to consciousness not necessary for all neurobiological processes?

5. The notion of confidence plays equally important role in understanding neuroscience of consciousness. While studying probabilistic computations, which the brain does, the notion of certainty and confidence are generally used as if they were synonyms. However, in the paper Confidence and Certainty: Distinct Probabilistic Quantities for Different Goals, the authors prove the opposite. "Specifically, we propose that confidence should be defined as the probability that a decision or a proposition, overt or covert, is correct given the evidence, a critical quantity in complex sequential decisions. We suggest that the term certainty should be reserved to refer to the encoding of all other probability distributions over sensory and cognitive variables" [Pouget et al., 2016].

The analysis of the studies in the field of the neuroscience of consciousness allow us to come to the next step, namely to consideration of the neural basis of lifelong learning.

\section{The neural basis of lifelong learning}

The neuroscience of consciousness studies enrich the model of education proposed by Oleg Bazaluk and Tamara Blazhevych [Bazaluk \& Blazhevych, 2015]. In fact, the Global Neuronal Workspace, Recurrent Processing Theory, Higher-Order Theories, and Information Integration Theory of Consciousness reveal a modern understanding of the neural basis of knowledge. However, since the subject of our study is lifelong learning as the future human need, let us consider the neural basis of lifelong learning. 
The neuroscience of consciousness study help us make two key interim conclusions:

1. The consciousness work directly depends on the amount of knowledge imprinted in the corresponding neural populations.

2. The neuroscience of consciousness develops in ontogenesis. Consciousness is not a static phenomenon, but a dynamic process that depends on various aspects, including factors of the internal and external environment.

Those are two of the postulates, on which we will base the further reasoning. We will prove that lifelong learning is due to neurobiological processes, and is, in fact, the brain need. Just as physical culture is necessary for the full development of biological functions of the organism, so a special culture, lifelong learning, is necessary for the full development of the neuroscience of consciousness.

The neuroscience of consciousness studies are convincing us that consideration of lifelong learning, as "a major component of sustainable economic growth and social cohesion reinforcement" is incomplete [Panitsidou et al., 2012]. Policy papers, which systematize and regulate integration processes in Europe, have been examined in the article European Union Policies on Lifelong Learning: In-between Competitiveness Enhancement and Social Stability Reinforcement [Panitsidou et al., 2012]. However, unfortunately, in considering all the documents, the authors do not specify and do not mention that, in fact, they document only the externals of lifelong learning as culture. The externals of human define the neural basis of consciousness. The combination of the neuroscience of consciousness and adult learning forms lifelong learning as culture, as the future human need.

Let us consider the neural basis of lifelong learning and its externals.

Firstly, the neuroscience of consciousness studies showed that the development of consciousness directly depends on work with knowledge quality. In fact, work with knowledge is necessary for the brain just as physical training is necessary for the body. Here, the Latin phrase "Mens sana in corpore sano" sounds literally, as the Roman poet Juvenal understood it: "You should pray for a healthy mind in a healthy body."

Consciousness is an open system, which is in need of work with knowledge. Moreover, work with knowledge should be understood much broader than it is commonly considered in modern education. It is by no means limited to school and university. According to the neurobiological research, up to twenty years education only forms the neural basis of consciousness. This basis is not sustainable and ultimate. It is dynamic, so it can both degrade and evolve. Everything depends on the environment in which it continues to develop. The lifelong learning need is explained by the peculiarity of the neural basis of consciousness: as a dynamic process, consciousness is in need of work with knowledge. The work with knowledge is the only way to continuously develop and maintain the neuroscience of consciousness.

The first conclusion from our study follows from the Global Neuronal Workspace, Recurrent Processing Theory, Higher-Order Theories, and Information Integration Theory of Consciousness: lifelong learning is a prerequisite for the continuous development of the neuroscience of consciousness. In fact, lifelong learning should be considered as the culture that creates favorable conditions for the development of the neuroscience of consciousness and its maximum complete self-realization in external environment, in society.

Secondly, the importance of the influence of knowledge on the formation and development of the neural basis of consciousness in ontogenesis forces us to rethink the very term "knowledge". In dealing with a neural basis of consciousness, the term "knowledge" is not synonymous with the term "information". The term "knowledge" for the neuroscience of consciousness implies the element of action, of coercion. More precisely, "knowledge" 
for neural basis of consciousness is coercion to acts; it is coercion, attention, self-reflection, etc. Information is something that surrounds consciousness and does not cause its reaction; and knowledge is something that puts it to work. Therefore, it follows the second conclusion of our research: lifelong learning is the culture coercing self-development. It focuses on the development of the neuroscience of consciousness, on the achievement of its maximum boundaries of self-expression.

Thirdly, consideration of lifelong learning as the culture, which ensures the full development of the neuroscience of consciousness, reveals the possibility to use the ideas of transhumanism in neurobiology. ${ }^{2}$ In the article Physical Education Teachers' Perspectives in a Changing World: From Future Studies to New Physical Culture, we have considered physical culture, as an artificial environment, that provides a consistent transformation of the body, as a biological organism, into the cybernetic organism [Voitovska \& Tolochko, 2018]. We believe that lifelong learning, as culture of full development of the neuroscience of consciousness in ontogenesis, should create the conditions for involvement in the cognitive process of high technology, in particular, information and communications technology, including mobile technologies and broadband.

Involving transhumanism ideas in neuroscience, and, in particular, in the neuroscience of consciousness, provides possibilities for expanding the natural frontiers of knowledge due to the capabilities of information and communications technologies. In fact, lifelong learning, as culture is designed to ensure the integration of the natural processes of neuroevolution with intensively developing information and communications technology, including mobile technologies and broadband. Possible results of such a symbiosis are examined in the article Cyborg, Mutant, Androgyne: The Future Human Being - What Will It Be Like? (Issues of Philosophy of Education) [Matusevych \& Bazaluk, 2015]. We can supplement the works of Tetiana Matusevych and Oleg Bazaluk with our observations and conclusions:

1. Development of consciousness in ontogenesis and development of high technology correlates. The very nature brings us to the understanding of the unity of natural processes and high technology.

2. For consciousness, high technology is not just a way to expand natural opportunities. It is the need; it is the involvement of high technology in neuroevolution and the achievement of an exponential increase in the efficiency of conscious activity.

3. We admit the full integration of neuroevolution with the development of high technology, when it becomes impossible to view the neuroscience of consciousness in isolation from high technology.

\section{Lifelong learning as the need}

Therefore, neural basis of consciousness appears to be the dynamic process that reach the highest development only in a certain environment, in lifelong learning as culture. The need to develop neural basis of consciousness in ontogenesis forces us to rethink current educational technologies used in lifelong learning. We are to broaden the traditional understanding of lifelong learning as Learning to Be, which includes: Learning to know; Learning to do; Learning to be; Learning to live together. ${ }^{3}$

Lifelong learning as culture differs significantly from education in its classic understanding. If education unifies consciousness and influences the neural basis of consciousness in general, then lifelong learning is mainly self-education. In considering lifelong learning as

${ }^{2}$ See [Voitovska \& Tolochko, 2018].

${ }^{3}$ See [Keevy \& Chakroun, 2015]. 
culture, it is not quite correct to interpret it as follows: "Lifelong learning may be non-formal or formal, public or private, provided online, or in communities and life situations such as intergenerational, peer-based and self-directed learning" [Keevy \& Chakroun, 2015: 27]. It is primarily, an opportunity to make an independent choice of educational technologies that meet the individual psyche needs. Accordingly, lifelong learning as culture should be regarded as a set of educational technologies, used for self-education, self-development and self-perfection that is for individual work with knowledge. The majority of educational technologies used in schools and universities lose their relevance in lifelong learning. The difference between twenty-year, forty-year and sixty-year brain neural basis of consciousness is significant. The difference lies both in its structure and in its functioning. Therefore, the technologies used in lifelong learning must meet individual needs and satisfy consciousness individual needs, regardless of age or period of ontogenesis. Their specific feature is as follows: lifelong learning technologies must become the consciousness need. Taking into account the fact that consciousness chooses them individually and under its own special structure, then lifelong learning technologies must meet consciousness individual needs, and stimulate the development of its structure and functions in such a way.

The technologies, used in lifelong learning, should stimulate consciousness to action, to development. Their use in everyday life is addictive, thereby ensuring the development of neural basis of consciousness. Thanks to technologies, lifelong learning consciousness gets used to action, to activity. Consciousness refers to lifelong learning as need, as natural environment for itself, in which it discovers the stimulants necessary for its development, high technologies that motivate action. Lifelong learning constitutes the consciousness need, ensuring the continuous development of its neural basis.

\section{Conclusions}

Thus, we have come to the conclusion that lifelong learning appears to be the necessary condition for the continuous development of the neuroscience of consciousness. This is a special culture, which forces consciousness to self-development in ontogenesis. The lifelong learning need as culture is conditioned by the dynamic neural basis of consciousness, which requires special conditions for full development in ontogenesis. As culture, lifelong learning has certain sets of educational technologies that develop the neurobiological basis of consciousness, stimulate consciousness action. Lifelong learning technologies are in need of work with knowledge; development of neural basis; development of attention, memory, and other neural populations. In general, lifelong learning as culture encourages maximum development and self-realization of consciousness in ontogenesis. The formation of stereotypes of aggressiveness or peacefulness, ${ }^{4}$ tolerance and orientation towards intercultural communication; ${ }^{5}$ etc., depends on lifelong learning. Lifelong learning, as culture, turns into a rich set of educational technologies for individual use, which not only meets the individual needs of consciousness in self-development, but also becomes the consciousness need, the future human need.

\section{References}

Bazaluk, Oleg. Postmodernism: Philosophy of Education. Future Human Image, 2 (5), 2015: 9-22.

\footnotetext{
${ }^{4}$ See, for example [Bazaluk \& Svyrydenko, 2017].

${ }^{5}$ See, for example [Rudenko et al., 2018].
} 
Bazaluk, Oleg. The Theory of Evolution: From a Space Vacuum to Neural Ensembles and Moving Forward. Cambridge Scholars Publishing, 2016.

Bazaluk, Oleg, and Tamara Blazhevych. Modern Basics of the Philosophy of Education. Future Human Image. 2 (5), 2015: 93-100.

Bazaluk, Oleg and Denys Svyrydenko. Philosophy of War and Peace: In Search of New European Security Strategy. Anthropological Measurements of Philosophical Research, 12, 2017: 89-99. https://doi.org/10.15802/ampr.v0i12.119150

Chun, Marvin M., Julie D. Golomb, and Nicholas B. Turk-Browne. A Taxonomy of External and Internal Attention. Annual Review of Psychology. 62, 2011: 73-101. https://doi. org/10.1146/annurev.psych.093008.100427

Grimaldi, Piercesare, Hakwan Lau, and Michele A. Basso. There Are Things That We Know That We Know, and There Are Things That We Do Not Know We Do Not Know: Confidence in Decision-Making. Neuroscience \& Biobehavioral Reviews, Volume 55, August 2015, 2015: 88-97. https://doi.org/10.1016/j.neubiorev.2015.04.006

Keevy, James, and Borhene Chakroun. Level-setting and recognition of learning outcomes: The use of level descriptors in the twenty-first century. UNESCO, 2015. http:// unesdoc.unesco.org/images/0024/002428/242887e.pdf

Koch, Christof, Marcello Massimini, Melanie Boly, and Giulio Tononi. Neural Correlates of Consciousness: Progress and Problems. Nature Reviews Neuroscience, 17(5), 2016: 307-321. https://doi.org/10.1038/nrn.2016.22

Lau, Hakwan, and David Rosenthal. Empirical Support for Higher-Order Theories of Conscious Awareness. Trends in Cognitive Sciences. 15 (8), 2011: 365-373. https:// doi.org/10.1016/j.tics.2011.05.009

Matusevych, Tetiana, and Oleg Bazaluk. Cyborg, Mutant, Androgyne: The Future Human Being - What Will It Be Like? (Issues of Philosophy of Education). Dialogue and Universalism, 25 (2), 2015: 175-181.

Panitsidou, Eugenia, Eleni Griva, and Dora Chostelidou. European Union Policies on Lifelong Learning: In-between Competitiveness Enhancement and Social Stability Reinforcement. $4^{\text {th }}$ World Conference on Educational Sciences (WCES-2012). Volume 46, 2012, Pages 548-553. https://doi.org/10.1016/j.sbspro.2012.05.158

Pouget, Alexandre, Jan Drugowitsch, and Adam Kepecs. Confidence and Certainty: Distinct Probabilistic Quantities for Different Goals. Nature Neuroscience, 19(3), 2016: 366374. https://doi.org/10.1038/nn.4240

Rudenko, Sergii, Roman Sapeńko, Oleg Bazaluk, and Vadym Tytarenko. Management Features of International Educational Projects between Universities of Poland and Ukraine. Naukovyi Visnyk Natsionalnoho Hirnychoho Universytetu. 2, 2018: 142147. https://doi.org/10.29202/nvngu/2018-2/21

Spener, Maja. Calibrating Introspection. Philosophical Issues, 25(1), 2015: 300-321. https:// doi.org/10.1111/phis.12062

Tononi, Giulio. An Information Integration Theory of Consciousness. BMC Neuroscience. 5, 42, 2004. DOI: 10.1186/1471-2202-5-42. https:/www.ncbi.nlm.nih.gov/pmc/articles/ PMC543470/

Voitovska, Oksana, and Svitlana Tolochko. Physical Education Teachers' Perspectives in a Changing World: From Future Studies to New Physical Culture. Philosophy and Cosmology, Volume 20, 2018: 139-145. https://doi.org/10.29202/phil-cosm/20/13

Wu, Wayne. The Neuroscience of Consciousness. The Stanford Encyclopedia of Philosophy, 2018. https://plato.stanford.edu/entries/consciousness-neuroscience/ 